\title{
QUANTIFICATION OF HIGH MOLECULAR WEIGHT $(1 \rightarrow 3)(1 \rightarrow 4)-\beta$-D-GLUCAN USING CALCOFLUOR COMPLEX FORMATION AND FLOW INJECTION ANALYSIS. I. ANALYTICAL PRINCIPLE AND ITS STANDARDIZATION
}

\author{
by
}

KIM G. JØRGENSEN

Department of Biotechnology, Carlsberg Research Laboratory, Gamle Carlsberg Vej 10, DK-2500 Copenhagen Valby

Keywords: Fluorescence, high performance size exclusion chromatography

\begin{abstract}
An automatic flow injection analysis (FIA) system based on the specific complex formation between Calcofluor and soluble high molecular weight $\beta$-glucan was devised. The fluorescence intensity of the complex, in a solution is proportional to the concentration of $\beta$-glucan molecules with a molecular weight above $10^{4}$. For calibration, standards with known purity of $\beta$-glucan are required. Four preparations differing in MW distribution and purity gave similar calibration values. Comparison of the Calcofluor-FIA method with the enzymatic method of MCCLEARY and GLENNIE-HOLMES ( 8 ) showed a high correlation between the values obtained by two methods. The water soluble $\beta$-glucan fraction of grains from 23 barley varieties was determined by both methods and yielded a linear correlation coefficient of $r=0.976$ between the two procedures.
\end{abstract}

\section{INTRODUCTION}

Quantification of the major barley endosperm cell wall component, the polysaccharide $(1 \rightarrow 3)(1 \rightarrow 4)$ - $\beta$-D-glucan ( $\beta$-glucan), is of fundamental interest to the malting and brewing industry, since it has been found that high levels of $\beta$-glucan in the grain retard malt modification and high amounts of $\beta$-glucan in wort and beer increases viscosity and cause filtration problems (2). Therefore, low amounts of $\beta$-glucan in malt are an important marker for the good malt quality $(1,4)$.

In an aqueous solution the fluorescence intensity of the fluorochrome Calcofluor increases by the addition of soluble $\beta$-glucan $(13,14)$. In a previous study this reaction was used with the flow injection analysis technique (FIA) to make rapid measurements of $\beta$-glucans in wort and beer (5).

In the present study, the suitability of different preparations of $\beta$-glucan for obtaining calibration curves is tested by comparing their purity employing acid and enzymatic hydrolysis and by determining the MW distribution with high performance size exclusion chromatography (HPSEC).

Using water soluble $\beta$-glucan extracted from different barley varieties the results obtained with the developed Calcofluor-FIA method are compared with the $\beta$-glucan contents deter-

Abbreviations: $\beta$-glucan = mixed linkage $(1 \rightarrow 3)(1 \rightarrow 4)-\beta$-D-glucan; D.M. $=$ dry matter; $D M S O=$ dimethyl sulfoxide; FIA = flow injection analysis; $\mathrm{HPSEC}=$ high performance size exclusion chromatography; $\mathrm{MW}=$ molecular weight. 
Table $1.65{ }^{\circ} \mathrm{C}$ water extractable $\beta$-glucan from 23 barley varieties quantified by the Calcofluor-FIA and Enzymatic methods.

(a) - Proanthocyanidin-free type, (b) - malting type, (c) - High Lysine type. (I, II) - Grown at different locations.

\begin{tabular}{|c|c|c|c|c|}
\hline Variety & Type & $\begin{array}{l}\text { Year and } \\
\text { location }\end{array}$ & $\begin{array}{l}\quad \beta \text {-glucan (\% } \\
\text { Calcofluor-FIA } \\
\text { method }\end{array}$ & $\begin{array}{l}\text { D.M.) } \\
\text { Enzymatic } \\
\text { method }\end{array}$ \\
\hline 1. Ant-13-13 & $\mathrm{a}$ & 1981 DK-I & 0.75 & 0.76 \\
\hline 2. Keti & & 1981 DK-I & 1.42 & 1.28 \\
\hline 3. Ca-56928 (Ant-13×Lami) & a & 1981 DK-I & 0.76 & 0.79 \\
\hline 4. Lami & & 1981 DK-I & 0.80 & 0.78 \\
\hline 5. Ca-57163 (Ant-13×Nordal) & a & 1981 DK-I & 1.09 & 1.06 \\
\hline 6. Nordal & b & 1981 DK-I & 0.43 & 0.51 \\
\hline 7. Georgie & $\mathrm{b}$ & 1981 DK-I & 0.92 & 0.92 \\
\hline 8. Ant- 180 & a & 1981 DK-I & 0.70 & 0.77 \\
\hline 9. Galant & a & 1981 DK-I & 1.66 & 1.50 \\
\hline 10. Ant-13×Rupal & $\mathbf{a}$ & 1982 DK-I & 1.63 & 1.51 \\
\hline 11. Catrin & $\mathrm{b}$ & 1982 DK-I & 1.41 & 1.36 \\
\hline 12. Ca-705708 (Ant-13×Kristina) $\times$ Kristina & a & 1982 DK-I & 0.99 & 0.97 \\
\hline 13. Ca-718017 (Ant-13×Ca-28348) & a & 1982 DK-I & 0.68 & 0.70 \\
\hline 14. Variety mix & $\mathrm{b}$ & 1982 DK-I & 0.90 & 0.86 \\
\hline 15. Triumph & $\mathrm{b}$ & 1982 DK-I & 0.74 & 0.78 \\
\hline 16. Nordal & $\mathrm{b}$ & 1982 DK-I & 0.64 & 0.65 \\
\hline 17. M-737 (Minerva mutant) & $\mathrm{b}$ & 1982 DK-I & 0.95 & 0.80 \\
\hline 18. M-892 (Minerva mutant) & $\mathrm{b}$ & 1982 DK-I & 0.66 & 0.60 \\
\hline 19. N-5247 (Nordal mutant) & $\mathrm{b}$ & 1982 DK-I & 0.85 & 0.70 \\
\hline 20. Ant-214 & a & 1982 DK-I & 0.75 & 0.77 \\
\hline 21. Galant & $\mathrm{a}$ & 1983 DK-II & 1.12 & 0.94 \\
\hline 22. Ca-700202 (Ca-49722×Triumph) & $\mathrm{c}$ & 1983 DK-I & 0.45 & 0.33 \\
\hline 23. Ca-901873 (Ca-11734×Galant) & a & 1984 DK-I & 1.07 & 0.93 \\
\hline
\end{tabular}

mined by the enzymatic method of MCCLEARY and GlenNiE-Holmes (8).

In an accompanying article (6), the total $\beta$-glucan content of grains from barley, other cereals and malt has been quantified using the FIA system.

\section{MATERIALS AND METHODS}

\subsection{Materials}

23 barley varieties (Table I) were used for extraction of water soluble $\beta$-glucan (section 2.3).

Five $\beta$-glucan preparations were used for a calibration study: two commercial available barley $\beta$-glucans, batch nos. 22752 and 515052 from Biocon Ltd., Victoria, Australia and Biocon Ltd., Worcestershire, UK, respectively. One lichenan purified from Iceland moss, batch no.
60584 was from Koch-Light Laboratories Ltd., UK. One preparation purified from the oat variety Hinoat was kindly supplied by Dr. $P$. WoOD, Agriculture Canada, Ottawa, Canada. One preparation was made from pearled Minerva barley according to the method of PREECE and MACKenziE (9). Calcofluor ${ }^{\mathrm{TM}}$ was from Polysciences Ltd., Northampton, UK. The enzymatic $\beta$-glucan assay kit was obtained from Biocon Ltd., Worcestershire, UK. A GOD-Perid glucose assay was from Boehringer Mannheim $\mathrm{GmbH}$, Germany. All other chemicals used were of analytical grade.

\subsection{Automatic detection of $\boldsymbol{\beta}$-glucan}

\subsubsection{The apparatus}

The automatic system for measuring $\beta$-glucan in wort and beer using flow injection analysis 


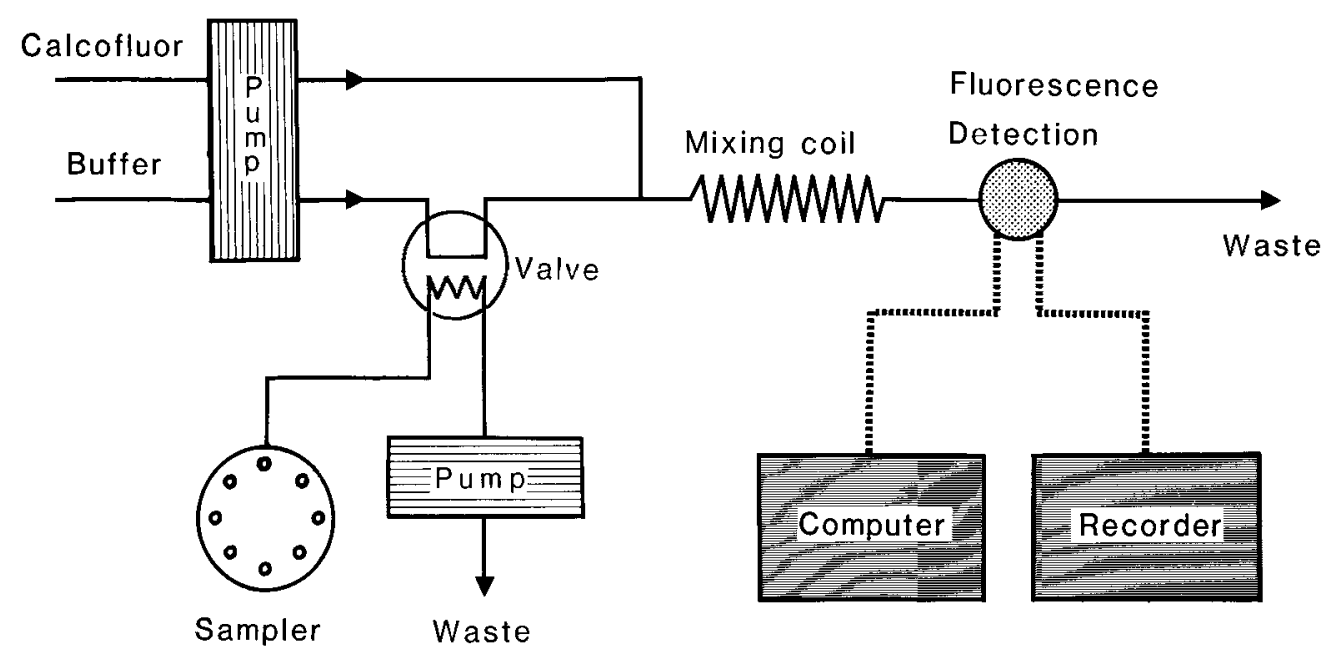

Figure 1. Diagram of the FIA apparatus used for automatic $\beta$-glucan analysis.

(FIA) has been described previously (5). In the present study, the system was devised as shown in the diagram (Figure 1). It consists of two peristaltic pumps (Ventur Tekniska A/B, Stockholm, Sweden), a valve with a $10 \mu \mathrm{l}$ sample loop, (5011P, Rheodyne, Cotati, California, USA), a fluorescence detector mounted with an $8 \mu$ flow through cuvette, (RF-530, Shimadzu, Kyoto, Japan) set at $350 \mathrm{~nm}$ and $425 \mathrm{~nm}$ for excitation and emission, respectively. Mixing was performed with a T-piece made of capillary steel mounted in a block of PVC. Sampling was performed automatically with a sampler (AS-40, Jasco, Tokoy, Japan). Control of sampler, valve and sample pump, and automatic data collection was done using a BBC microcomputer, (Acorn, Cambridge, UK). The signal output from the fluorescence detector was also monitored on a recorder, (REC-61, Radiometer, Emdrup, Denmark).

A solution of carrier buffer $(0.2 \mathrm{M}$-glycine/ $\mathrm{NaOH}$ buffer; $\mathrm{pH} 10$ ) and a reagent consisting of a $0.0025 \%(\mathrm{w} / \mathrm{v})$ solution of Calcofluor in the same buffer were delivered at $2.0 \mathrm{~mL} \cdot \mathrm{min}^{-1}$. The increase in fluorescence intensity developed when Calcofluor complexes with $\beta$-glucan (13, 14) was monitored with the fluorimeter and maximum fluorescence intensity (peak height) was automatically found by the connected computer. The sample rate was set for 1 injection per
$35 \mathrm{sec}$. The Calcofluor solution was made fresh every day from a $0.1 \%$ stock solution and kept in a brown bottle to avoid photodecomposition.

\subsubsection{Quantification of $\beta$-glucan contents}

Standards with known amount of $\beta$-glucan were used to calculate the $\beta$-glucan content of extracts.

Fifty $\mathrm{mg}$ of a $\beta$-glucan preparation was placed in a $200 \mathrm{ml}$ volumetric flask, $100 \mathrm{ml}$ deionized water was added, and the $\beta$-glucan dissolved by placing the flask in a boiling waterbath for $1 / 2 \mathrm{~h}$ followed by $2 \mathrm{~h}$ of continuous stirring with a magnetic bar. After cooling and removal of the bar, $\mathrm{NaN}_{3}$ was added to a final concentration of $0.1 \%$, the volume was adjusted and the solution finally filtered through a $2 \mu \mathrm{m}$ Millipore membrane filter. This standard stock solution could be stored at $4{ }^{\circ} \mathrm{C}$ for several months before use.

For obtaining the standard curve, aliquots of the stock solution were diluted with deionized water to a final volume of $5 \mathrm{ml}$, containing 0,50 , $100,150,200$ and $250 \mathrm{mg} \cdot \mathrm{L}^{-1}$ of the preparation, respectively. A calibration curve giving the relation between fluorescence and $\mathrm{mg} \cdot \mathrm{L}^{-1}$ of the given preparation was obtained by linear regression. The $\beta$-glucan content of an extract was calculated as follows:

$\beta$-glucan $\left(\mathrm{mg} \cdot \mathrm{L}^{-1}\right)=(\mathrm{AxF}+\mathrm{B}) \times 0.9 \times \mathrm{PF}$ 
$\mathrm{F}=$ Digitized maximum increase in fluorescence intensity of sample

A $=$ Slope of regression line (typical value: 400 $\left(\mathrm{mg} \cdot \mathrm{L}^{-1}\right) /(\mathrm{mV})$ )

$\mathrm{B}=$ Intercept of regression line (typical value: $\left.0.5 \mathrm{mg} \cdot \mathrm{L}^{-1}\right)$

$\mathrm{PF}=$ Purity factor of the $\beta$-glucan preparation used for calibration, expressed as g glucose per g preparation

$0.9=$ Conversion factor between the glucose monomer of $\beta$-glucan ( $\mathrm{MW}=162)$ and the determined glucose of the hydrolysed $\beta$ glucan $(\mathrm{MW}=180)$.

Expressed as content of the flour in percent of dry matter (D.M.):

$\beta$-glucan (\% D.M. $)=\left(\beta\right.$-glucan $\left.\left(\mathrm{mg} \cdot \mathrm{L}^{-1}\right)\right) \times$

$\mathrm{V} /((100-\mathrm{M}) \times \mathrm{W}) \times 10,000$

$\mathrm{V}=$ Extraction volume (typical value: $0.020 \mathrm{~L}$ )

$\mathrm{M}=$ Moisture content of flour sample (e.g. $10.2 \%)$

$\mathrm{W}=$ Weight of sample in $\mathrm{mg}$

The purity factor (PF) was determined by two methods:

1) By acid hydrolysis: $50 \mathrm{mg} \beta$-glucan was accurately weighed into a $100 \mathrm{~mL}$ volumetric flask. $50 \mathrm{~mL} 1 \mathrm{M}-\mathrm{H}_{2} \mathrm{SO}_{4}$ was added and the $\beta$-glucan polymer hydrolysed to glucose by placing in boiling water for $2 \mathrm{~h}$. The solution was cooled and the volume adjusted with $\mathrm{H}_{2} \mathrm{O}$. An aliquot was centrifuged $(1,000 \times \mathrm{g} ; 10 \mathrm{~min})$ and glucose in the supernatant measured using the phenol/ $\mathrm{H}_{2} \mathrm{SO}_{4}$ method (3).

2) By the enzymatic $\beta$-glucan method of MCCleary and GlenNie-Holmes (8). The glucose released from the specifically degraded $\beta$-glucan was measured using the GOD-Perid reagent from Boehringer.

For estimation of the $\beta$-glucan contents of sample extracts, purified $\beta$-glucan from Biocon batch no. 22752 was used in the calibration.

\subsection{Extraction of water soluble $\boldsymbol{\beta}$-glucan}

Flour was produced by grinding the seeds $(50-100 \mathrm{~g})$ in a Tecator Udy Cyclon grinder fitted with a $0.5 \mathrm{~mm}$ screen. The flour was carefully mixed before samples for analysis were taken.

Fifty $\mathrm{mg}$ of barley flour was weighed into a
$26 \times 100 \mathrm{~mm}$ pyrex test tube with teflon lined screw cap. Twenty ml of $80 \%(\mathrm{v} / \mathrm{v})$ ethanol was added and the sample placed in boiling water for $1 \mathrm{~h}$ to destroy any enzyme activity. The tube was centrifuged $(1,000 \times \mathrm{g} ; 10 \mathrm{~min})$ and the supernatant discarded. Ten $\mathrm{ml}$ of deionized water and a magnetic stirrer were added and the $\beta$-glucan was extracted by continuously stirring in a mashing bath set at $65^{\circ} \mathrm{C}$ for $1 \mathrm{~h}$. The extract was centrifuged $(1,000 \times \mathrm{g} ; 10 \mathrm{~min})$ and the $\beta$-glucan in the supernatant was measured using both the Calcofluor-FIA method and the enzymatic method. All measurements were carried out in duplicate.

\subsection{High performance size exclusion chromatography (HPSEC)}

Chromatography was performed with an ionpak- 805 column $(500 \times 8 \mathrm{~mm})$ mounted with a precolumn 800-P (Shodex, Showa Denko K.K., Minato, Japan). The columns were kept at $60^{\circ} \mathrm{C}$ with a column oven (Microlaboratoriet, Århus, Denmark). Degassed and filtered $(0.45 \mu \mathrm{m}$ membrane filter) eluent DMSO: $\mathrm{H}_{2} \mathrm{O}$ (distilled) $25: 75 \%(\mathrm{v} / \mathrm{v})$ was delivered at $0.8 \mathrm{ml} \cdot \mathrm{min}^{-1}$ with a Waters HPLC pump (Waters, Milford, USA). $100 \mu \mathrm{l}$ of degassed and filtered $\beta$-glucan solution was injected with an injector (Valco, Texas, USA). Refractive index was monitored using an Optilab multiref 5002 detector (Tecator, Höganäs, Sweden) and the chromatograms were recorded (C-R3A integrator, Shimadzu, Kyoto, Japan). According to manufacturers' data, the column system separates dextrans (pullulan) in the range from $1 \times 10^{4}$ to $5 \times 10^{6}$ in molecular weight. Total volume $\left(V_{t}\right)$ of the column system was estimated with glucose and the exclusion column $\left(\mathrm{V}_{0}\right)$ estimated using data from the manufacturers.

Preparations of purified $\beta$-glucan were dissolved in the eluent to a concentration of 0.5 $\mathrm{mg} \cdot \mathrm{mL}^{-1}$.

\section{RESULTS}

\subsection{The automatic $\beta$-glucan analyser}

The complex formation between high molecular weight $\beta$-glucan and Calcofluor resulting in an increase in Calcofluor fluorescence intensity 


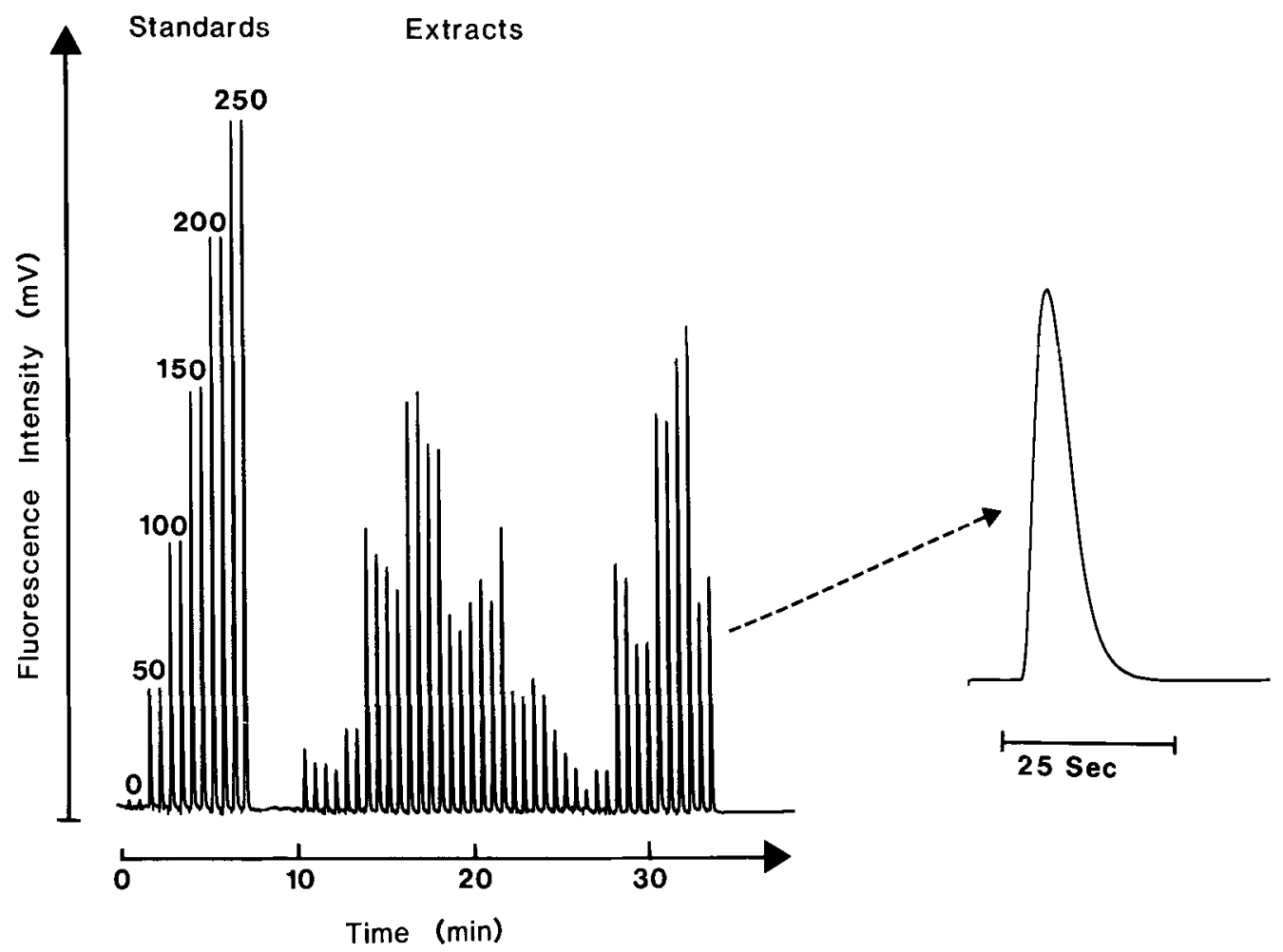

Figure 2. Recorded responses from the $\beta$-glucan analyser. Duplicate standard samples used for calibration are shown to the left, the values above the peaks show the concentration in $\mathrm{mg} \cdot \mathrm{L}^{-1}$ and these are followed by the responses of analysed barley flour extracts. A sample monitored at high chart speed is shown to the right.

was used to measure solubilized $\beta$-glucan in the FIA apparatus (Figure 1). Recorded outputs from the system are shown in Figure 2, for some $\beta$-glucan standards and flour extracts. The recorded output was found to give a typical FIA peak (10), as illustrated by the fluorescence response recorded at high chart speed (Figure 2, right).

As the reaction between Calcofluor and $\beta$-glucan is very sensitive, the system was designed with a large dispersion of $D=20$ (D value as defined by RUZICKA and HANSEN (10)) in order to quantify the $\beta$-glucan concentration within a proper linear working range $0-250 \mathrm{mg} \cdot \mathrm{L}^{-1}$. The ratio between maximum fluorescence of the Calcofluor/ $\beta$-glucan complex and the Calcofluor alone was found to be about 2.5 at maximum concentration of the standard (e.g. $250 \mathrm{mg} / \mathrm{L}$ ). Despite the relatively high background fluorescence caused by the Calcofluor dye alone, the

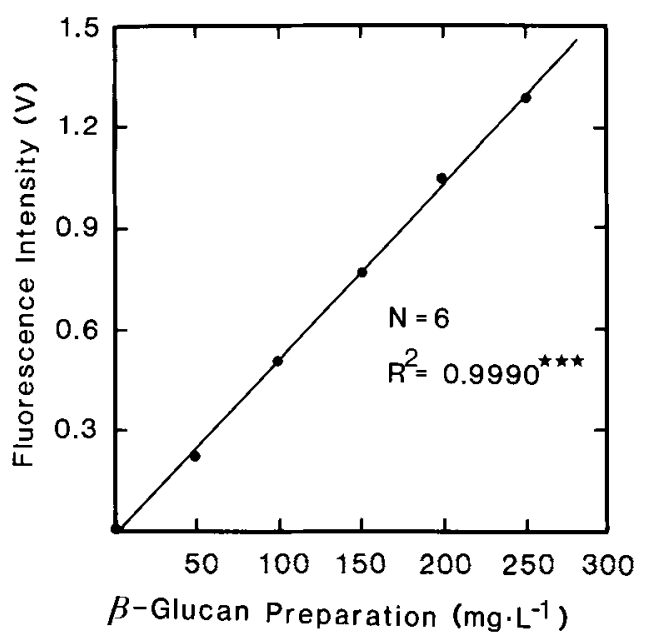

Figure 3. Standard curve used to calibrate the $\beta$-glucan analysis. Concentration of the $\beta$-glucan preparation from Biocon (batch no. 22752) plotted against the digitized maximum fluorescence increase (peak height) of the individual dilutions. 


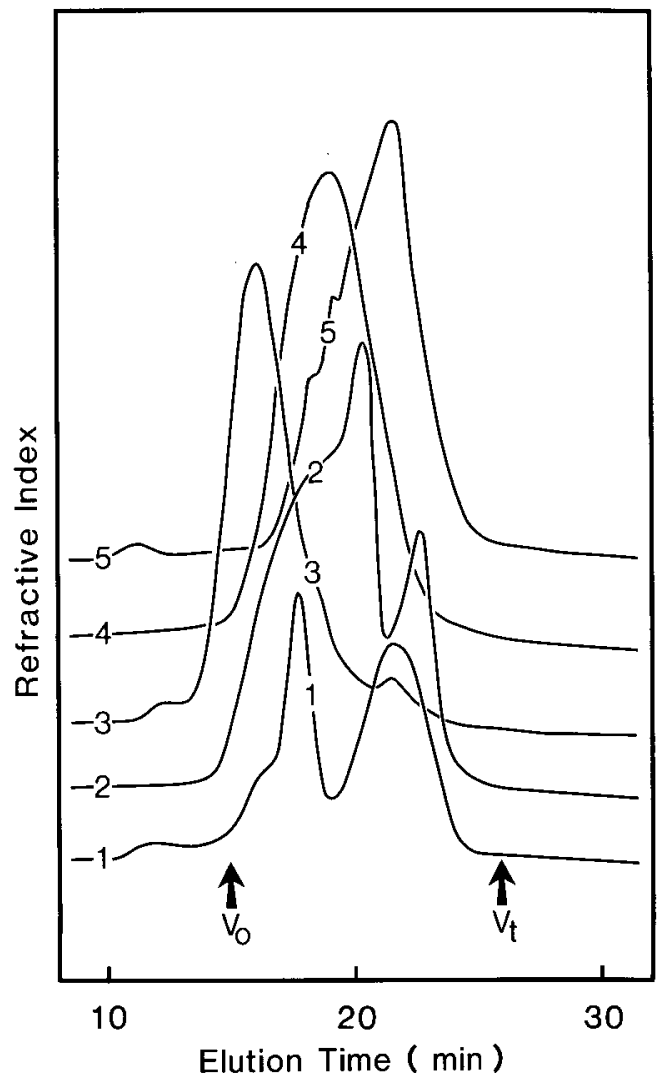

Figure 4. Molecular weight characterization of purified $\beta$-glucan preparations by HPSEC. $1=$ lichenan, 2 $=$ Biocon batch no. 515052, $3=$ oat $\beta$-glucan, $4=$ Biocon batch no. $22752,5=$ barley $\beta$-glucan purified from Minerva.

errors caused by variation in the operation of the injection valve, mixing procedure and other components was found to be less than $1 \%$. Negligible fluctuations in the baseline were observed during several hours of operation.

\subsection{Calibration of the $\beta$-glucan analyser}

The quantification of $\beta$-glucan was based on a calibration to a standard solution of purified $\beta$-glucan (section 2.2.2). A linear relationship was observed, when the concentration of a $\beta$-glucan preparation was plotted against the recorded fluorescence intensity (Figure $3 ; \mathrm{N}=6$, $\left.\mathrm{R}^{2}=0.9990\right)$. In a recent study (5), it has been shown that only $\beta$-glucan with a molecular weight larger than $5 \times 10^{4}$ induces a concentration proportional increase in the fluorescence intensity of Calcofluor upon complex formation. However, preparations of $\beta$-glucan purified by different procedures may vary in molecular size and purity. Therefore, investigations were carried out in order to find a simple way to ensure a valid and accurate calibration independent of the calibration standard used.

Five different sources of $\beta$-glucan were studied. The preparations (section 2.1) included 3 isolates from barley, one from oat and one from Iceland moss. The latter was included, because its structure is very similar to the barley and oat $\beta$-glucans (11), and because it could provide a relatively inexpensive and readily available source of $\beta$-glucan.

A characterization of the five preparations with regard to MW distribution was first carried outs by HPSEC (Figure 4). All the preparations were found to have MW greater than the lower limit of the column $\left(V_{t}, M W \approx 10^{4}\right)$, but considerable variations in $\mathrm{MW}$ distributions were noted among the preparations. The one made from oat, shown as chromatogram no. 3 , was found to have the largest amounts of high MW molecules. The lichenan (no. 1) and one of the commercial barley $\beta$-glucan preparations (Biocon, batch no. 515052 , no. 2) separated into two defined fractions with different molecular weight distributions. The two $\beta$-glucan preparations from the same supplier (no. 2 and no. 4) displayed distinct difference in their MW profiles. The chromatogram of the Minerva barley $\beta$-glucan (no. 5) showed a very high proportion of low MW molecules.

A standard curve analogous to that shown in Figure 3 was generated for each of the other $\beta$-glucan preparations. A test solution with a $\beta$-glucan content giving a maximum fluorescence intensity of about $0.6 \mathrm{~V}$ (Figure 3) was then determined as described in section 2.2 , using each of the five different $\beta$-glucan preparations as calibrated standards. The purity of the preparations were analyzed by hydrolysis of the preparations with sulfuric acid and determination of the glucose content and alternatively by hydrolysis of an aliquot with the enzymatic test of McCleary and GlenNIE-Holmes (Table II) (8). The actual content of glucose per g glucan 
Table II. Comparison of the characteristics of 5 different $\beta$-glucan preparations with regard to purity and their uses as standards for the Calcofluor-FIA method. The $\beta$-glucan content of a test solution was measured by the Calcofluor-FIA method based on a calibration line derived from each of the different $\beta$-glucan preparations and the corresponding purity factor (PF), as described in the formula in section 2.2.

\begin{tabular}{l|ll|ll}
\hline $\begin{array}{l}\text { B-glucan } \\
\text { preparation }\end{array}$ & $\begin{array}{l}\text { Purity factor }(\mathrm{PF}) \\
\text { determined by acid } \\
\text { hydrolysis. } \\
\text { g glucose per } \\
\text { g preparation }\end{array}$ & $\begin{array}{l}\text { Calcofluor-FIA } \\
\text {-glucan } \\
\text { estimate of } \\
\text { test solution } \\
\left(\mathrm{mg} \cdot \mathrm{L}^{-1}\right)\end{array}$ & $\begin{array}{l}\text { Purity factor }(\mathrm{PF}) \\
\text { determined by } \\
\text { enzymatic hydrolysis. } \\
\text { g glucose per } \\
\text { g preparation }\end{array}$ & $\begin{array}{l}\text { Calcofluor-FIA } \\
\beta \text {-glucan } \\
\text { estimate of } \\
\text { test solution } \\
\left(\mathrm{mg} \cdot \mathrm{L}^{-1}\right)\end{array}$ \\
\hline 1. Lichenan & 0.952 & 87.8 & 0.927 & 85.5 \\
2. Biocon 515052 & 0.658 & 99.7 & 0.652 & 98.8 \\
3. Oat & 0.876 & 105.1 & 0.826 & 99.1 \\
4. Biocon 27752 & 1.010 & 98.1 & 1.020 & 98.5 \\
5. Minerva & 0.890 & 108.1 & 0.795 & 96.6 \\
\hline
\end{tabular}

preparation is called the purity factor $(\mathrm{PF})$ and used to correct the $\beta$-glucan content measured by the fluorescence method according to the formula derived in section 2.2 .

From the glucose released by acid hydrolysis (Table II, column 1) it is evident that the Biocon preparation no. 2 contained the lowest amount of carbohydrate $(0.658 \mathrm{~g}$ glucose per $\mathrm{g}$ preparation) and the other Biocon preparation (no. 4) the highest amount ( $1.01 \mathrm{~g}$ glucose per $\mathrm{g}$ preparation). In estimating the $\beta$-glucan content of the test solution (Table II, column 2 ) by correcting the fluorescence values for the amount of glucose per g preparation (section 2.2.2), the two Biocon preparations gave values for $\beta$-glucan content which differed only by $1.6 \%$. It was thus certified, that determinations of the carbohydrate content in $\beta$-glucan preparations could be used to obtain consistent values of $\beta$-glucan content in a test solution by fluorescence measurement of the $\beta$-glucan-calcofluor complex. The amount of glucose released by acid hydrolysis of preparations nos. 1, 3 and 4 (Table II, column 1) was observed to lie between the two Biocon preparations. Correction of the fluorescence values by the amount of glucose in the preparations gave for the test solution using the oat and the Minerva preparations $6-8 \%$ higher values and for the Lichenan a $10 \%$ lower value when compared to the estimates obtained by the Biocon preparations used as standards.

When the amount of glucose released by the enzymatic treatment of the $\beta$-glucan prepara- tions (section 2.2) was determined, it was found that the Biocon preparations yielded the same amount of glucose monomers as with acid hydrolysis (Table II, column 3). However, the lichenan, the oat and the Minerva $\beta$-glucan preparations yielded significantly less glucose after enzymatic than after acid hydrolysis indicating that they contain impurities of other non $\beta$-glucan carbohydrate. If the fluorescence values are corrected by the content of glucose per $g$ preparation released by the enzymes, nearly identical estimates of the $\beta$-glucan content of the test solution were obtained (Table II, column 4). Only the calibration based upon lichenan was different, indicating that this lichenan preparation complexes with calcofluor differently than the cereal $\beta$-glucan preparations. Disregarding the lichenan, a $2.5 \%$ difference between the lowest estimate (using the Minerva preparation) and the highest (using the oat preparation) was observed.

\subsection{Water extraction $\beta$-glucan}

By using solutions of highly purified $\beta$-glucan, or by determining the amount of $(1 \rightarrow 3)(1 \rightarrow 4)-\beta$ $D$-glucan in a solution by the enzymatic method, an accurate calibration of the $\beta$-glucan analyser could be achieved. The Calcofluor-FIA method was further tested by measuring the $65{ }^{\circ} \mathrm{C}$ water-soluble $\beta$-glucan fraction of barley flour (section 2.3) from different varieties by the enzymatic method and by the fluorescence 


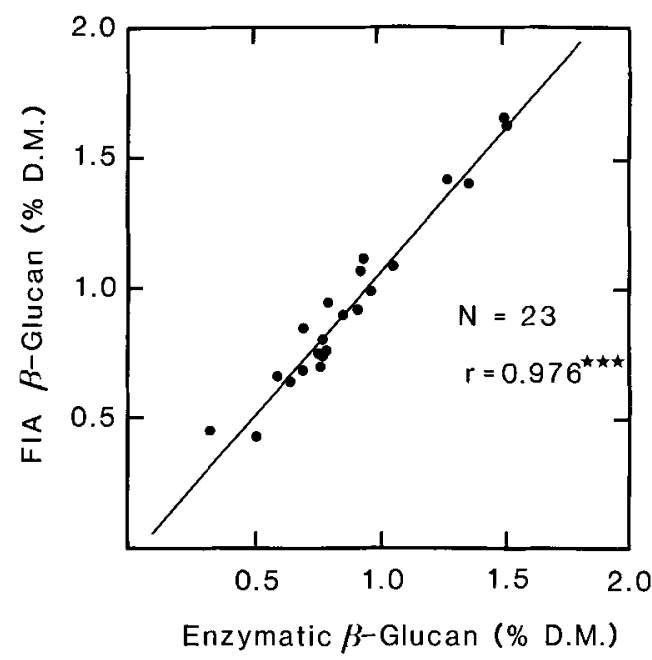

Figure 5. The relationship between $65^{\circ} \mathrm{C}$ water extractable $\beta$-glucan measured enzymatically and by the use of the $\beta$-glucan analyser (Calcofluor-FIA method), regression line: "FIA $\beta$-glucan" (\% D.M.) $=1.11 \times$ "Enzymatic $\beta$-glucan" - 0.05 (\% D.M.)

method. The results are shown in Table I and Figure 5, and indicate a high correlation between the values obtained by the two methods $(\mathrm{N}=23, \mathrm{r}=0.976)$. The obtained regression can be described by the equation "FIA $\beta$-glucan (\% D.M.)" = $1.11 \times$ "Enzymatic $\beta$-glucan" -0.05 (\% D.M.). Thus similar values for $\beta$-glucan content of the extracts are obtained by the two methods.

\section{DISCUSSION}

\subsection{The suitability of using FIA}

FIA of the reaction complex ( $\beta$-glucan with Calcofluor) forms a very sensitive and rapid method for the detection of $\beta$-glucan. The reaction between Calcofluor and $\beta$-glucan can be used in a manual analytical procedure, e.g. by mixing of dye and sample in a test tube and performing the measurements of the complexes in a spectrofluorimeter. However, the FIA technique provides several advantages besides the speed by which a large number of analyses can be carried out in an automated process. Calcofluor is degraded by light (12) which requires that the time and intensity of exposure to light of the sample (exposure to both external light before measurement in the laboratory or to excitation light during measurement) must be controlled. In a FIA apparatus time dependence is automatically under full control because the time from injection to analysis is constant (10). In addition, the actual time of exposure to light of the sample fraction in the cuvette in the apparatus is very short and uniform due to the continuous flow system (i.e. $30 \mathrm{~ms}$ for the present system). Thus as the photodecomposition of Calcofluor is minimal with the FIA technique a high intensity of light can also be used for excitation.

\subsection{Calibration}

Unlike other methods for measuring $\beta$-glucan, the present method uses the undegraded polymer for calibration. This requires that the content of $\beta$-glucan of the sample used for calibration is known. It was possible to establish a calibration independent of the $\beta$-glucan source, by four cereal sources of $\beta$-glucan, despite the fact that they were very different in respect to MW distribution above $10^{4}$ dalton. However, the $\beta$-glucan source of non cereal origin (lichenan from Iceland moss) could not be used as a calibration source. A different ratio between the amount of measured $\beta$-glucan and increase in fluorescence intensity was found when compared with the cereal $\beta$-glucan sources. From a study by $\operatorname{WoOD}(12,13)$ it was found that different types of polysaccharides containing glucose linked by $\beta$-linkages respond differently to Calcofluor in respect to increase in fluorescence intensity. A possible explanation for the results in this study could be that although the cereal $\beta$-glucans differ in MW distribution, their primary structures are very similar. It would be expected that a marked different ratio in $\beta 1,3$ to $\beta 1,4$ linkages and in the organization of glucose linked in the polymer by these linkages would alter the respond to Calcofluor. As reported by WOODWARD et al. (15) water soluble barley $\beta$-glucan consists mainly of 3-4 units of glucose monomers linked together by $\beta 1,4$ linkages and separated by single $\beta 1,3$ linkages.

Comparing the Calcofluor binding method 
with the enzymatic method described by MCCLEARY and GleNNIE-Holmes (8) it was shown that the same values are obtained when measuring the water soluble $\beta$-glucan fraction of barley (Figure 5). However, this may be valid only when the $\beta$-glucan fraction is high in MW (above $10^{4}$ dalton), as the Calcofluor-FIA method exclusively measures high MW $\beta$-glucan, whereas the enzymatic method does not make this differentiation. This is aiso illustrated by the fact that a pre-precitation of the high MW $\beta$-glucan is necessary when using the enzymatic method for measuring the troublesome high MW $\beta$-glucan fraction of wort or beer (7). Such a pre-precipitation is for obvious reasons not necessary when using the Calcofluor-FIA $\beta$-glucan analysis.

\section{ACKNOWLEDGEMENTS}

I wish to express my sincere gratitude to Fil.Dr. LARS MunCK for supporting this work. The advice of my colleagues Dr. S. AASTRUP, Dr. K. Erdal, Dr. B.S. Enevoldsen, Prof. D. von WetTSTEIN and Dr. R.G. FulChER, and the skilful technical assistance by Mrs. L. FREDERIKSEN, Mrs. E. MEILING, Mr. M. JACOBSEN and Mr. K.T. HANSEN is greatly appreciated.

\section{REFERENCES}

1. Aastrup, S. \& K. ERDAL: Quantitative determination of endosperm modification and its relationship to the content of 1,3:1,4- $\beta$-glucan during malting of barley. Carlsberg Res. Commun. 45, 369-379 (1980)

2. BAMFORTH, C.W.: Barley $\beta$-glucans, their role in malting and brewing. Brew. Dig., June, 22-35 (1982)

3. Dubois, M., K.A. Gilles, J.K. Hamilton, P.A. ReBERS \& F. SMITH: Colorimetric method for determination of sugars and related substances. Anal. Chem. 28, 3, 350-356 (1956)
4. JøRGENSEN, K.G. \& S. AASTRUP: Analysis of $\beta$-glucan in wort. Proc. Eur. Brew. Conv. Symp., Monograph XI, Maffliers, 262-273 (1986)

5. Jørgensen, K.G., S.A. Jensen, P. HartleV \& L. MUNCK: The analysis of $\beta$-glucan in wort and beer using Calcofluor. Proc. Eur. Brew. Conv. Congr., Helsinki, 403-410 (1985)

6. JøRGENSEN, K.G. \& S. AASTRUP: Quantification of high molecular weight $(1 \rightarrow 3)(1 \rightarrow 4)-\beta$-D-glucan using Calcofluor complex formation and flow injection analysis. II. Determination of total $\beta$-glucan content of barley and malt. Carlsberg Res. Commun. 53, 287-296 (1988)

7. MCCleary, B.V.\& N. NuRthen: Measurement of $(1 \rightarrow 3)(1 \rightarrow 4)-\beta$-D-glucan in malt, wort and beer. $\mathrm{J}$. Inst. Brew. 92, 168-173 (1986)

8. McCleary, B.V. \& M. Glennie-Holmes: Enzymatic quantification of $(1 \rightarrow 3)(1 \rightarrow 4)-\beta$-D-glucan in barley and malt. J. Inst. Brew. 91, 285-295 (1985)

9. Preece, I.A. \& K.G. MacKenzie: Non-starchy polysaccharides of cereal grains. I. Fractionation of the barley gums. J. Inst. Brew. 58, 353-362 (1952)

10. RUZICKA, J. \& E.H. HANSEN: Flow injection analysis. Chemical analysis. Vol. 62, John Wiley \& Sons, New York (1981)

11. Tvaroska, I., K. OGawa, Y. Deslandes \& R.H. MARCHESSAULT: Crystalline conformation and structure of lichenan and barley $\beta$-glucan. Can. J. Chem. 61, 7, 1608-1616 (1983)

12. WoOD, P.J.: Specificity in the interaction of direct dyes with polysaccharides. Carbohydr. Res. 85 , 271-287 (1980)

13. WoOD, P.J.: Factors affecting precipitation and spectral changes associated with complex formation between dyes and $\beta$-D-glucans. Carbohydr. Res. 102, 283-293 (1982)

14. WoOd, P.J., R.G. FulcheR \& B.A.STONE: Studies on the specificity of interaction of cereal cell wall component with Congo red and Calcofluor. Specific detection and histochemistry of $(1 \rightarrow 3),(1 \rightarrow 4)-\beta-D-g l u c a n$. J. Cereal Sci. 1, 95-110 (1983)

15. WOODWARD, J.R., G.B. FINCHER \& B.A.STONE: Water-soluble $(1 \rightarrow 3),(1 \rightarrow 4)-\beta$-D-Glucans from barley (Hordeum vulgare) endosperm. II. Fine structure. Carbohydr. Polymers 3, 207-225 (1983) 